\title{
Genetic differentiation of eastern wolves in Algonquin Park despite bridging gene flow between coyotes and grey wolves
}

\author{
LY Rutledge ${ }^{1}$, CJ Garroway ${ }^{1}$, KM Loveless ${ }^{1,3}$ and BR Patterson ${ }^{2}$ \\ ${ }^{1}$ Environmental and Life Sciences Graduate Program, Trent University, Peterborough, Ontario, Canada and ${ }^{2}$ Wildlife Research \\ and Development Section, Ontario Ministry of Natural Resources, Trent University, Peterborough, Ontario, Canada
}

\begin{abstract}
Distinguishing genetically differentiated populations within hybrid zones and determining the mechanisms by which introgression occurs are crucial for setting effective conservation policy. Extensive hybridization among grey wolves (Canis lupus), eastern wolves (C. lycaon) and coyotes (C. latrans) in eastern North America has blurred species distinctions, creating a Canis hybrid swarm. Using complementary genetic markers, we tested the hypotheses that eastern wolves have acted as a conduit of sex-biased gene flow between grey wolves and coyotes, and that eastern wolves in Algonquin Provincial Park (APP) have differentiated following a history of introgression. Mitochondrial, $Y$ chromosome and autosomal microsatellite genetic data provided genotypes for 217 canids from three geographic regions in Ontario, Canada: northeastern Ontario, APP and southern Ontario. Coyote mitochondrial DNA (mtDNA) haplotypes were common across regions but coyote-specific $\mathrm{Y}$ chromosome
\end{abstract}

haplotypes were absent; grey wolf mtDNA was absent from southern regions, whereas grey wolf $Y$ chromosome haplotypes were present in all three regions. Genetic structuring analyses revealed three distinct clusters within a genetic cline, suggesting some gene flow among species. In APP, however, $78.4 \%$ of all breeders and 11 of 15 known breeding pairs had assignment probability of $Q \geqslant 0.8$ to the Algonquin cluster, and the proportion of eastern wolf $Y$ chromosome haplotypes in APP breeding males was higher than expected from random mating within the park $(P<0.02)$. The data indicate that Algonquin wolves remain genetically distinct despite providing a sex-biased genetic bridge between coyotes and grey wolves. We speculate that ongoing hybridization within the park is limited by pre-mating reproductive barriers.

Heredity (2010) 105, 520-531; doi:10.1038/hdy.2010.6; published online 17 February 2010

Keywords: assortative mating; conservation; eastern wolf; gene flow; genetic cline; introgressive hybridization

\section{Introduction}

Hybridization between animal species is considered by some to be one of the greatest threats to biodiversity (Rhymer and Simberloff, 1996). As more hybrid animal populations are identified, however, hybridization is increasingly recognized as a natural evolutionary process represented as an ongoing ebb and flow of hybridizationspeciation events in response to environmental variables over time (Seehausen, 2004; Mallet, 2005). This new outlook challenges how conservation biologists view hybridization and its role in speciation, but remains problematic for setting conservation guidelines (Allendorf et al., 2001) because it disrupts the foundation of conservation policies based largely on the biological species concept proposed by Dobzhansky (1937) and Mayr (1942). The difficulty persists because interpreta-

Correspondence: Dr LY Rutledge, Environmental and Life Sciences, Trent University, DNA Building, 2140 East Bank Drive, Peterborough, Ontario, Canada K9J 7B8.

E-mail: lrutledge@nrdpfc.ca

${ }^{3}$ Current address: Montana Department of Fish, Wildlife and Parks, Missoula, MT 59801, USA.

Received 22 September 2009; revised 25 November 2009; accepted 21 December 2009; published online 17 February 2010 tion of the biological species concept suggests that complete reproductive isolation is a prerequisite for speciation, even though most species concepts, including the biological species concept, allow for some genetic exchange between species (Futuyma, 2005; Arnold, 2006). The requirement of reproductive isolation is especially problematic for conservation when species are part of a hybrid swarm, where introgressive hybridization with various levels of backcrossing has occurred between two or more species. Although these challenges could be alleviated by restructuring policies to focus on conserving evolutionary potential, identifying legitimate conservation units in hybrid populations under the current framework remains difficult.

Across Ontario, genomes from three different Canis species, grey wolves (C. lupus), eastern wolves (C. lycaon) and western coyotes (C. latrans), are represented in various hybridized forms, creating a three-species hybrid complex (Wilson et al., 2009; Wilson et al., in review) or syngameon. In contrast, grey wolves and coyotes in western North America, outside the historic range of eastern wolves (Rutledge et al., 2009), show no evidence of hybridization (Pilgrim et al., 1998). In fact, grey wolves aggressively limit coyotes, sometimes with fatal consequences (Berger and Gese, 2007; Merkle et al., 2009). 
It has been proposed that Canis hybridization flourished in eastern North America because of the presence of the eastern wolf, an intermediate-sized canid, that mediated gene flow between grey wolves and coyotes (Wheeldon and White, 2009; Wilson et al., 2009).

There has also been speculation that ecological factors may be promoting selection on morphological and genetic variation among contemporary Canis hybrid populations in Ontario (Wilson et al., 2009). Body size is notably different among the different regions with an increase in size along a latitudinal gradient, where animals in southern regions of Ontario are smaller than the intermediate-sized animals in Algonquin Provincial Park (APP), which in turn are smaller than those found in northern Ontario (Kolenosky and Standfield, 1975; Sears et al., 2003; Holloway, 2010; Figure 1). Presumably, selection is influenced by differences in prey availability (Carmichael et al., 2001; Muñoz-Fuentes et al., 2009) in the different regions, with larger ungulates such as moose (Alces alces) and woodland caribou (Rangifer tarandus) predominant in northern regions, intermediate-sized prey such as white-tailed deer (Odocoileus virginianusvirginianus) and beaver (Castor canadensis) being common along with moose in APP, and smaller prey in southern Ontario such as cottontail rabbit (Sylvilagus floridanus), groundhog (Marmota monax) and muskrat (Ondatra zibethicus), which exist sympatrically with abundant white-tailed deer populations. Moose have been a fluctuating presence in APP since the early 1900s (Quinn, 2005), but Algonquin wolves have typically preyed primarily on deer (Pimlott et al., 1969; Forbes and Theberge, 1996). Recent work, however, suggests that they may now be effective moose predators (Loveless, 2010). The regional prey base coincides with the broader landscape features of Ontario: northeastern Ontario $(\mathrm{NEON})$ is primarily a remote boreal forest; APP is a protected area representing a zone that is transitional between deciduous forest south and coniferous forests north of the park; and southern Ontario is predominantly

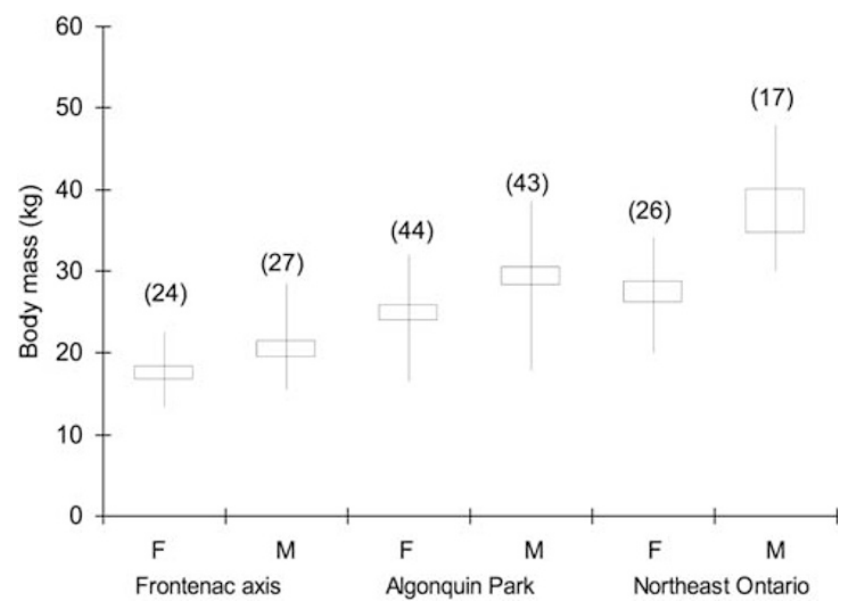

Figure 1 Relative weights $(\mathrm{kg})$ of Canis hybrids from three regions of Ontario, Canada. Boxes represent the mean and 95\% confidence intervals, whereas the whiskers indicate the range of values for each category. Sample sizes are given in parentheses. Weights from the Frontenac Axis were taken from Sears (1999), those from northeast Ontario were taken from Holloway (2010) and those from Algonquin Park were compiled from captures associated with pedigree analysis (Rutledge et al., 2010). M, male; F, female. farmland with scattered deciduous forest patches and urban areas.

Characterizing the mechanisms, extent and timing (ancient, 11000 years ago; historic, approximately 60-100 years ago and/or ongoing) of Canis hybridization in eastern North America, and identifying post-hybridization differentiation are important for setting effective conservation policy in Canada and the United States. Previous research has suggested that eastern wolves in APP represent the southern extent of a larger metapopulation (Grewal et al., 2004; Wilson et al., 2009). However, the recent development of advanced analytical tools for genetic and spatial data, combined with pedigree data, allows for a more detailed account of gene flow and differentiation in Ontario Canis populations. To that end, we used maternal, paternal and biparental markers to generate genetic data on 217 Canis animals from three different geographic regions in Ontario: eastern coyotes (C. latrans $x$ lycaon) from southern Ontario along the Frontenac Axis (FRAX), nominal eastern wolves (C. lycaon that have introgressed western coyote (C. latrans) and grey wolf (C. lupus) genetic material) from APP, and grey wolf hybrids (C. lupus $x$ lycaon) from NEON (Figure 2). Although we acknowledge the hybrid nature of these animals, for simplicity we refer to these groups as coyotes (FRAX), eastern wolves (APP) and grey wolves (NEON) throughout the remainder of the paper. These data, combined with pedigree data from APP (Rutledge et al., 2010), were used to test the following hypotheses: (1) eastern wolves in APP have acted as a conduit of gene flow between grey wolves north of the park and coyotes south of the park; (2) hybridization events were historically gender biased with males of the larger species breeding with females of the smaller species and (3) eastern wolves in APP are a distinct genetic group despite ancient/historic hybridization with grey wolves and coyotes.

\section{Materials and methods}

Sample collection, DNA extraction and genetic profiling Canis blood or tissue samples were collected and sample locations were recorded in three different geographic regions across Ontario: NEON $(n=51)$, APP $(n=128)$ and FRAX $(n=38)$ (Figure 2). Samples from NEON were randomly selected from a data set of wolflike canids (Wheeldon, 2009). Based on assignment tests conducted with the software program Structure 2.2 (Pritchard et al., 2000; http://pritch.bsd.uchicago.edu/structure.html), only 3 of the 109 samples in a source NEON data set were highly assigned as eastern coyotes $(Q>0.8)$, one was identified as an eastern wolf-coyote hybrid $(Q=0.453 ; 0.477)$ and none were identified as a grey wolf-eastern coyote (NEON-FRAX) hybrid (based on eastern coyote $Q \geqslant 0.2$ ) (Wheeldon TJ, unpublished data). Animals from FRAX were randomly selected from a larger data set described in Sears et al. (2003). In APP, samples were chosen from a larger data set based on pack affiliations and pedigrees (Rutledge et al., 2010) such that only unrelated individuals within a pack and animals not affiliated with a pack were included. Pups and related yearlings were excluded from the analysis, except in cases where one or both the breeding pairs were not identified, in which case one pup was included 


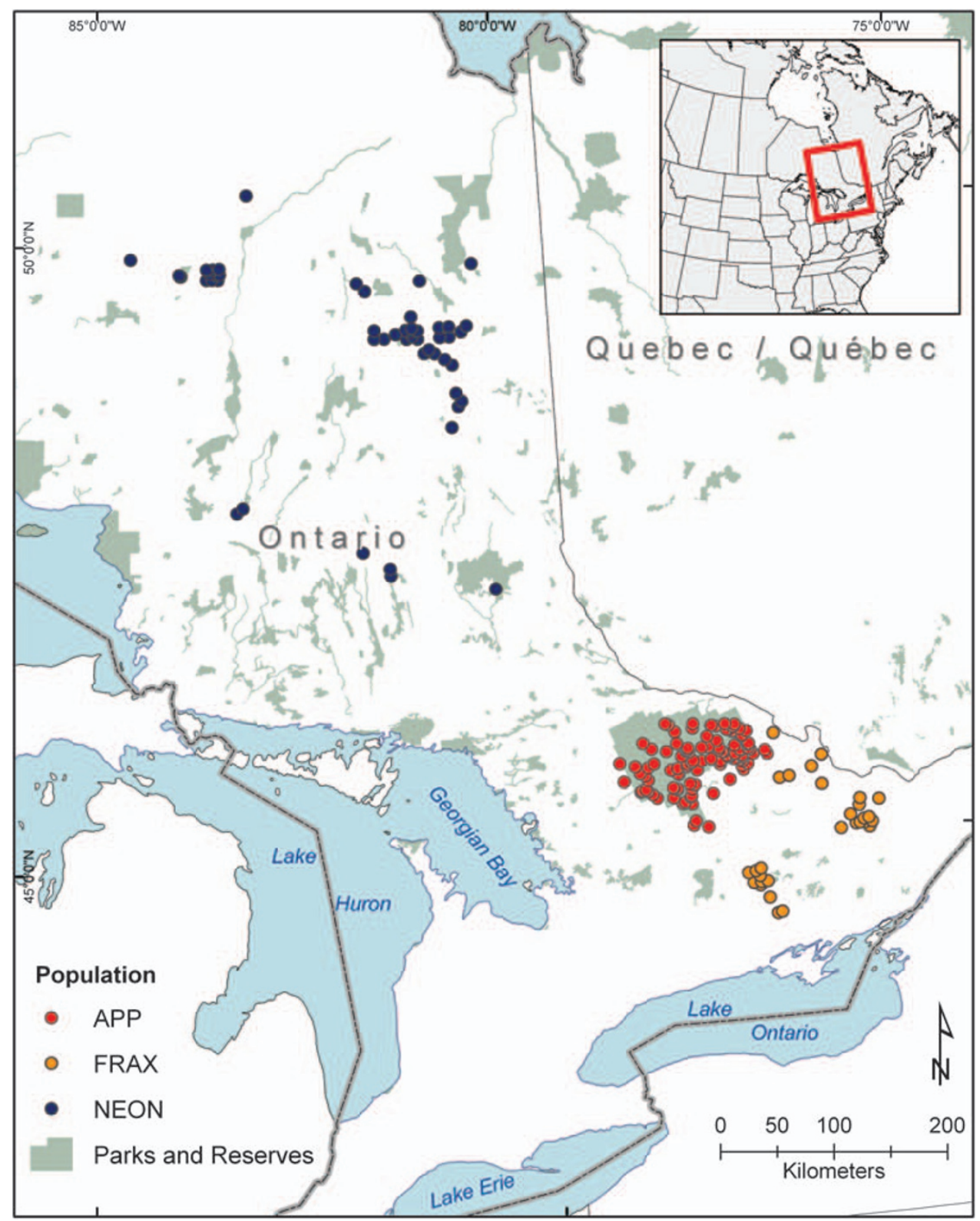

Figure 2 Map of the three sampling regions and locations of the Canis samples used in this study. APP, Algonquin Provincial Park; FRAX, Frontenac Axis in southern Ontario; NEON, northeastern Ontario.

as representative of the missing parental genome(s). On the basis of kinship analysis (Rutledge et al., 2010), animals identified as transient based on telemetry data were typically unrelated to each other. Although Canis spp. distribution is continuous between APP and NEON, samples from the region directly north of APP were unavailable. NEON and APP samples were extracted with a DNeasy Blood and Tissue kit (Qiagen, Mississauga, Ontario, Canada) according to the manufacturer's directions and those from FRAX were extracted as described in Grewal et al. (2004).

All samples were profiled at the mitochondrial DNA (mtDNA) control region with primers described in Wilson et al. (2000) and 12 autosomal microsatellite markers (cxx225, cxx200, cxx123, cxx377, cxx250, cxx204, cxx172, cxx109, cxx253, cxx442, cxx410 and cxx147; Ostrander et al., 1993, 1995) with conditions described in Wheeldon and White (2009). Gender was determined either by amplification at the Zfx/Zfy intron (Shaw et al., 2003) or with Zfx/Sry primer pairs (Aasen and Medrano, 1990; Fain and LeMay, 1995). Confirmed males were then profiled at $4 \mathrm{Y}$ chromosome microsatellite loci (MS34A, MS34B, MS41A and MS41B; Sundqvist et al., 2001) and at a $658 \mathrm{bp}$ fragment of the Zfy intron with primers LGL331 (5'-CAAATCATGCAAGGATAGAC-3'; Shaw et al., 2003) and Yint2-335 (5'-GTCCATTGGATAATTCTTTCC-3'; Shami, 2002). The polymerase chain reaction (PCR) chemical and cycling conditions for the $\mathrm{Y}$ chromosome microsatellite loci were as follows: For MS34, 5-10 ng of DNA was amplified in a $15 \mu \mathrm{l}$ reaction with $1 \times$ PCR buffer, $0.2 \mathrm{mM}$ dNTPs (Invitrogen, Burlington, Ontario, Canada), $1.5 \mathrm{mM} \mathrm{MgCl}_{2}, 0.1 \mu \mathrm{M}$ MS34A-F primer, $0.15 \mu \mathrm{M}$ MS34B-F primer, $0.2 \mu \mathrm{M}$ MS34-R primer and $1 \mathrm{U}$ Taq DNA polymerase (Invitrogen). PCR cycling included an initial 
denaturation at $94{ }^{\circ} \mathrm{C}$ for $5 \mathrm{~min}$ followed by 30 cycles of $94{ }^{\circ} \mathrm{C}$ for $30 \mathrm{~s}$, annealing at $60{ }^{\circ} \mathrm{C}$ for $1 \mathrm{~min}$ and extension at $72{ }^{\circ} \mathrm{C}$ for $1: 00$, with a final cycle of $60^{\circ} \mathrm{C}$ for $45 \mathrm{~min}$ and storage at $4{ }^{\circ} \mathrm{C}$. Conditions for MS41 were similar to MS34, except that primer concentrations were $0.15 \mu \mathrm{M}$ MS41A-F primer, $0.2 \mu \mathrm{M}$ MS41B-F primer, $0.2 \mu \mathrm{M}$ MS41-R primer and the annealing temperature was $58^{\circ} \mathrm{C}$. The $\mathrm{Y}$ intron was amplified under the following PCR conditions in a $20 \mu \mathrm{l}$ reaction: approximately 5-10 ng of DNA, $1 \times$ PCR buffer, $0.2 \mathrm{mM}$ dNTPs, $1.5 \mathrm{mM} \mathrm{MgCl}_{2}, 0.2 \mathrm{mM}$ each primer, $0.1 \mu \mathrm{g}$ bovine serum albumin and $1 \mathrm{U}$ Taq DNA polymerase. PCR steps included initial denaturation at $94^{\circ} \mathrm{C}$ for $5 \mathrm{~min}$ followed by 35 cycles of $94{ }^{\circ} \mathrm{C}$ for $30 \mathrm{~s}, 52{ }^{\circ} \mathrm{C}$ for $30 \mathrm{~s}$ and $72{ }^{\circ} \mathrm{C}$ for $30 \mathrm{~s}$, followed by a final extension at $72{ }^{\circ} \mathrm{C}$ for $10 \mathrm{~min}$. All sequencing and microsatellite fragment separation and visualization were performed on a MegaBACE 1000 (G Healthcare, Baie d'Urfé, Quebec, Canada), with the exception of the NEON and FRAX $Y$ chromosome microsatellites that were analysed on an AB3730 (Applied Biosystems Canada, Streetsville, Ontario, Canada). All microsatellites were scored in GeneMarker 1.7 (SoftGenetics, State College, PA, USA).

Sequences were edited in BioEdit (Hall, 2007) and mtDNA sequences were assigned unique haplotype codes (Cx) identified in Wilson et al. (2000) and Grewal et al. (2004). Haplotypes C1 and C3 are considered eastern wolf specific based on previously published phylogenetic analyses (Wilson et al., 2000; Rutledge et al., 2009). Although haplotypes C9, C13 and C17 cluster phylogenetically with coyote haplotypes, leading some to interpret them as coyote specific (for example, Leonard and Wayne, 2008; Kays et al., 2010), they are interpreted here as eastern wolf specific because they are not known to occur in non-hybridized western coyote populations; their presence in eastern wolves is due to either incomplete lineage sorting or hybridization during the last glaciation event $\sim 11000$ years ago (Wheeldon and White, 2009). This assumption is reasonable, given the presence of coyote-like haplotypes in eastern wolves approximately 30-400 years before western coyote expansion (Wilson et al., 2003; Rutledge et al., 2009), and the assignment of a coyote-like sequence as red wolf (C. rufus) specific (Hailer and Leonard, 2008).

$Y$ intron sequences were identified as one of the four possible species-specific haplotypes (intron-1 (ancestral; GenBank accession no. FJ687618), intron-2 (grey wolf; GenBank accession no. FJ687619), intron-3 (coyote; accession number not available) or intron-4 (eastern wolf; GenBank accession no. FJ687620)) as described by Shami (2002) and Wilson et al. (in review). Y chromosome haplotypes associated with intron 1 are considered ancestral because introns 2, 3 and 4 each differ from intron 1 by only one nucleotide (Shami, 2002), although conservatively Intron 1 may be interpreted as a North American evolved Y chromosome haplotype that is shared between eastern wolves and coyotes (Wilson et al., in review). Y chromosome microsatellite haplotypes were assigned according to previously reported nomenclature (Grewal et al., 2004; Wilson et al., in review).

\section{Genetic diversity and differentiation}

Standard measures of genetic diversity in each of the three geographic regions were calculated in GenAlEx 6.1
(Peakall and Smouse, 2006). Traditional estimates of genetic differentiation based on $\mathrm{F}_{\mathrm{ST}}$ (Weir and Cockerham, 1984) and $R_{\mathrm{ST}}$ (Slatkin, 1995) were calculated and tests of significance were performed with 999 permutations in the AMOVA option of GenAlEx 6.1 (Peakall and Smouse, 2006). However, $F_{S T}$ is based on sample heterozygosity, and therefore differentiation can be underestimated when within-population heterozygosity is high or when heterozygosity varies among populations (Hedrick, 2005; Jost, 2008, 2009). In addition, $R_{\mathrm{ST}}$ assumes a stepwise mutation model for microsatellites that may not fully reflect how microsatellites evolve ( $\mathrm{Li}$ et al., 2002). As we were interested in comparing differentiation among the three nominal species, we also calculated the harmonic mean of Jost's $D_{\text {est }}$ (Jost, 2008) in the online program SMOGD version 1.2.5 (Crawford, 2009; http:/ / www.ngcrawford. com/django/jost/; accessed 19 August 2009) as a measure of absolute differentiation between regions. The $D_{\text {est }}$ measure is based on allele identities rather than ratios of heterozygosity.

\section{Bayesian and multivariate ordination analyses}

To determine genetic structuring and individual assignments based on the autosomal microsatellite data set, we used two different approaches: (1) Bayesian clustering assignments with and without spatial data implemented in the programs Geneland version 3.1.4 (Guillot et al., 2008) and Structure version 2.2 (Pritchard et al., 2000; Falush et al., 2003), respectively and (2) multivariate ordination methods with and without spatial components analysed by principal component analysis (PCA) and a spatial principal component analysis (sPCA) (Jombart et al., 2008), both implemented in the adegenet package (Jombart, 2008) of R 2.9.0 (R Development Core Team, 2008).

Using these methods in combination, one can assess the various assumptions and criticisms of each method when the combined results are interpreted. For example, Bayesian clustering programs such as Structure provide powerful analytical tools for identifying genetic structure in data sets, and similar programs such as Geneland incorporate spatial data to assess the influence that geography has on population structure (Coulon et al., 2006). However, both approaches assume that populations are in the Hardy-Weinberg equilibrium and that there is linkage equilibrium between loci, prerequisites that are often violated in natural populations. In contrast, multivariate ordination in a PCA does not require the data to meet those assumptions and thereby complements the Bayesian analyses. Recently, Jombart et al. (2008) suggested that Bayesian clustering may be inappropriate when populations are structured across a cline, and they developed a 'spatially explicit multivariate method' or sPCA that accounted for spatial structure and genetic variability and could identify different genetic structures, including clines, without having to meet the assumptions of Bayesian approaches. The sPCA complements the Bayesian approach implemented in Geneland by identifying more cryptic spatial patterns of genetic structuring across the landscape, and accounts for spatial autocorrelation issues associated with neighbour-mating and sample distribution (Schwartz and McKelvey, 2009). 
The number of clusters $(K)$ was estimated in Structure version 2.2 with no a priori population assignment of individuals under the admixture $\mathrm{F}$ model for correlated allele frequencies (Falush et al., 2003) with 5000000 MCMC steps and a burn-in of 250000 . Five runs, each of $K=1-8$, were used to determine the most likely number of clusters based on a combination of the mean estimated Ln probability of the data (Pritchard et al., 2000) and the second-order rate of change in the log probability of the data $(\Delta K)$ (Evanno et al., 2005). A total of 10 runs at $K=3$ were subsequently run under the same conditions and average $Q$ scores were used as the probability of assignment. Values of $Q \geqslant 0.8$ were considered 'pure' on the basis of standard assumptions in the literature and previous hybrid simulation analyses performed in $\mathrm{R}$ with a similar data set (L Rutledge, unpublished data). Individuals were considered 'admixed' if there was no single assignment of $Q>0.8$ and at least one secondary probability value was $Q \geqslant 0.1$.

The Geneland algorithm is similar to Structure in that it attempts to define clusters by maximizing HardyWeinberg equilibrium and linkage equilibrium. It differs in that it treats $K$ as a parameter to be estimated by the MCMC algorithm, and it can explicitly incorporate the spatial coordinates of individuals into its modelling procedure, which may be particularly important when examining spatial processes such as gene flow. Parameters were set as follows: 1000000 MCMC iterations, maximum rate of Poisson process was 100, and the uncertainty of spatial coordinates was $1 \mathrm{~km}$. With these parameters, the MCMC was run 10 times, allowing $K$ to vary between 1 and 10 to verify the consistency of the inferred K (Guillot et al., 2005). The MCMC was then run 25 more times with the same parameters but with $K$ fixed to the value inferred by the initial run. From this set, the run with the highest log posterior probability of population membership was selected for subsequent analyses. The posterior probability of population membership for pixels was computed with a burn-in of 500000 iterations and the number of pixels was set to 300 along both the $x$ and $y$ axes. Finally, the posterior probability of population membership was computed for pixels and the inferred population membership of individuals to model populations.

A centred, scaled PCA was used to cluster individual microsatellite genotypes. We chose to use PCA because it clusters individuals only on the basis of their genotypes and makes no assumptions regarding Hardy-Weinberg equilibrium or linkage equilibrium. Thus, it is a good option to corroborate inferences from the Structure analysis while making fewer assumptions regarding the underlying data structure. The PCA was implemented in the $\mathrm{R}$ statistical language ( $\mathrm{R}$ Development Core Team, 2008) with the adegenet (Jombart, 2008) and ade4 (Dray and Dufour, 2007) packages.

As noted by the authors of the Bayesian algorithms used here (Pritchard et al., 2000; Guillot et al., 2005) and recently shown by simulation (Frantz et al., 2009; Schwartz and McKelvey, 2009), deviations from random mating not caused by barriers to gene flow (that is, spatial autocorrelation and isolation by distance) and the sampling scheme can have impacts on the detection and interpretation of genetic structure. These include potential overestimation of genetic structure for data sets characterized by continuously distributed individuals and spatially autocorrelated allele frequencies (Frantz et al., 2009; Schwartz and McKelvey, 2009). sPCA (Jombart et al., 2008) explicitly incorporates spatial autocorrelation as well as variance into the clustering procedure. Similar to PCA, sPCA makes no assumptions regarding Hardy-Weinberg equilibrium or linkage equilibrium and thus provides a useful corroboration to the similarly spatial Geneland while making fewer assumptions. sPCA has another important feature that differs from the Structure, PCA and Geneland analyses: it can explicitly identify spatial clines. sPCA incorporates Moran's I (Moran, 1948, 1950) to detect spatial features in the data. A Gabriel graph (Legendre and Legendre, 1998) was constructed based upon individual sample locations to define neighbours for the calculation of Moran's I. sPCA then defines synthetic components that optimize the product of the variance and Moran's I, summarizing spatial patterns of genetic structure. These components are separated into positive (global) and negative (local) eigenvalues. Global scores can identify genetically distinguishable groups, clines in allele frequencies and intermediate individuals, whereas local scores can detect differentiation between neighbouring individuals. As with the PCA, the sPCA analysis was implemented in $\mathrm{R}$ with the adegenet (Jombart, 2008) and ade4 (Dray and Dufour, 2007) packages. Principal component values were interpolated as a function of $x$ and $y$ coordinates using a local least-squares regression and plotted with the 's.image' function in the ade4 package (Dray and Dufour, 2007) on a map of Ontario.

\section{Mating patterns}

To determine patterns of sex-biased hybridization events, we compiled mtDNA and Y chromosome haplotypes for all individuals. For identification of conspecific mating, breeders and breeding pairs (which tended to be unrelated) within the APP data set were identified based on previous pedigree analysis (Rutledge et al., 2010). Admixed individuals were identified as described in the Structure methods above. Both the assignment scores in Structure and the mtDNA and $\mathrm{Y}$ chromosome DNA haplotypes were identified for all APP breeders. To test whether mating patterns in APP were assortative for (1) the APP population, and (2) the data set as a whole, we used randomization tests (100 permutations) on the $\mathrm{Y}$ chromosome microsatellite haplotype data to determine whether the observed proportion of male breeders with eastern wolf $\mathrm{Y}$ chromosome haplotypes in APP differed from that expected if mating within APP were random. Based on the identification of 18 breeding males in APP, resampling of $18 \mathrm{Y}$ chromosome microsatellite haplotypes from those identified in all males (1) within APP and (2) across all regions was performed without replacement under the assumption that male wolves typically father offspring within only one pack.

\section{Results}

\section{Genetic diversity and differentiation}

Genetic diversity was high in all three geographic regions and each group showed evidence of private alleles (Table 1). Pairwise comparisons of genetic differentiation showed significant differentiation between groups, although $R_{\mathrm{ST}}$ values suggest a closer 
Table 1 Genetic diversity within Canis clusters

\begin{tabular}{lccccr}
\hline Cluster & $\mathrm{N}$ & $\mathrm{A}$ (s.e.) & $\mathrm{A}_{E}$ (s.e. & $\mathrm{H}_{O}$ (s.e.) & $\mathrm{H}_{E}$ (s.e.) \\
\hline APP & 128 & $7.58(0.657)$ & $3.561(0.333)$ & $0.645(0.041)$ & $0.678(0.043)$ \\
FRAX & 38 & $6.83(0.694)$ & $4.281(0.408)$ & $0.717(0.042)$ & $0.733(0.035)$ \\
NEON & 51 & $6.33(0.497)$ & $3.629(0.496)$ & $0.688(0.037)$ & $0.678(0.033)$ \\
\hline
\end{tabular}

Abbreviations: $A$, average number of alleles; $A_{\mathrm{E}}$, effective number of alleles; $A_{\mathrm{P}}$, number of private alleles; $H_{\mathrm{E}}$, expected heterozygosity; $H_{\mathrm{O}}$, observed heterozygosity; $N$, samples sizes.

Standard error (s.e.) is shown in parentheses.

Table 2 Pairwise comparisons of $\mathrm{F}_{\mathrm{ST}}$ (Weir and Cockerham, 1984), $R_{\mathrm{ST}}$ (Slatkin, 1995), and $D_{\text {est }}$ (Jost, 2008) among Canis clusters

\begin{tabular}{lccc}
\hline Measure & APP-FRAX & APP-NEON & NEON-FRAX \\
\hline $\mathrm{F}_{\text {st }}$ & $0.052(0.001)$ & $0.105(0.001)$ & $0.120(0.001)$ \\
$R_{\text {st }}$ & $0.029(0.007)$ & $0.008(0.06)$ & $0.194(0.001)$ \\
$D_{\text {est }}$ & 0.090 & 0.207 & 0.255 \\
\hline
\end{tabular}

For $\mathrm{F}_{\mathrm{ST}}$ and $R_{\mathrm{ST}}$, numbers in parentheses are $P$-values based on 999 permuations in the AMOVA option of GenAlEx 6.1 (Peakall and Smouse, 2006). $D_{\text {est }}$ is the harmonic mean across loci as calculated in SMOGD (Crawford, 2009).

relationship between APP and NEON than between APP and FRAX, whereas $\mathrm{F}_{\mathrm{ST}}$ and $D_{\text {est }}$ show APP as more closely related to FRAX than NEON (Table 2).

Bayesian and multivariate ordination analyses Bayesian clustering with Structure and Geneland converged on three groups (Figures $3 \mathrm{a}$ and $4 \mathrm{a}$ ). The high peak for $\Delta K$ at $K=2$ is interpreted as the broad separation 1-2 million years ago between the Old World (grey wolves) and New World (eastern wolves/red wolves and coyotes) lineages. Concordance between both estimation methods in Structure is found at $K=3$, which may reflect the more recent divergence among the New World species (approximately 150 000-300 000 years ago) (Wilson et al., 2000). Although there is clear differentiation among the three geographic regions and posterior probabilities in Geneland showed a strong association to each geographic region with a steep division between APP and FRAX (Figures $3 \mathrm{~b}$ and $4 a-d$ ), there is evidence of some admixture and migration (Figure $3 b)$. Both FRAX $(n=6 ; 15.8 \%)$ and NEON $(n=8$; $15.7 \%$ ) had animals admixed with APP, and APP had evidence of admixture with both FRAX $(n=14 ; 10.9 \%)$ and NEON $(n=8 ; 6.3 \%)$. Only two animals from NEON had evidence of FRAX hybridization, but both had $Q_{\text {FRAX }}<0.3$ (Figure $3 b$ ). Two animals were migrants from APP into FRAX $\left(Q_{\mathrm{APP}}=0.9821 ; 0.9248\right)$ and three migrated from FRAX to APP $\left(Q_{\mathrm{FRAX}}=0.9085 ; 0.9094\right.$; 0.8245), but no migrants were identified between FRAX and NEON (although known coyotes were excluded from the NEON data set because we were interested in sampling wolflike animals in this region; there was no evidence of NEON-FRAX hybridization in the original data set; see Materials and methods section for more details).

Similar to the Bayesian analyses, components 1 and 2 of the PCA clearly differentiated APP, NEON and FRAX, with APP intermediate to the other clusters but more closely associated with FRAX, although there is evidence of migration between the two groups (Figure 5). In the
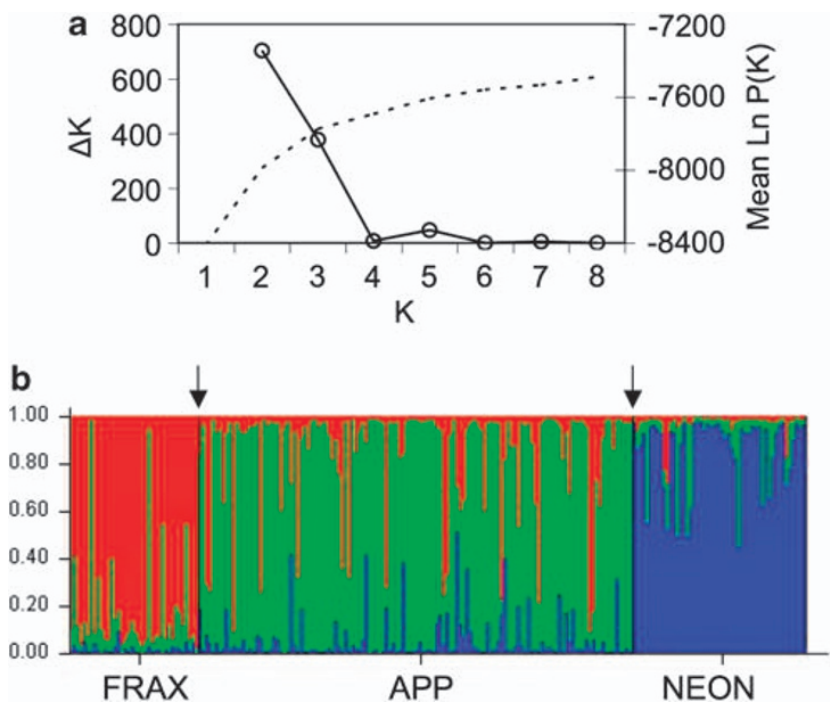

Figure 3 (a) Estimation of the number of Canis clusters (K). Dotted line is the mean Ln probability of the data $(\operatorname{Ln} P(K))$ (Pritchard et al., $2000)$ and the solid line is the second-order rate of change $(\Delta K)$ (Evanno et al., 2005), inferring that $K=3$. (b) Bayesian clustering and individual assignment output from the program Structure show genotypic clustering according to geographic regions with some evidence of admixture within each cluster. Arrows indicate divisions of geographic regions. Vertical axis is the probability of assignment $(Q)$ to each of the clusters, and the horizontal axis represents the categories of geographic regions sampled: APP, Algonquin Provincial Park; FRAX, Frontenac Axis in southern Ontario; NEON, northeastern Ontario.

sPCA, three global components appeared to be important. Interpolation using a locally weighted regression (LOESS) of component 1 scores from the sPCA illustrated a cline in allele frequencies from south to north (Figure 6), supporting the contention that eastern wolves in APP act as a conduit for gene flow between coyotes in the FRAX regions and grey wolves in the NEON region. Subsequent sPCA components clustered the populations similar to the other clustering methods (data not shown).

\section{Mating patterns}

Patterns of mtDNA and $\mathrm{Y}$ chromosome haplotype distributions across the three geographic regions were generally consistent with the hypothesis that introgression was directional with females of the smaller species historically mating with males of the larger species (Tables 3 and 4). Sex-biased introgression was clearly evident when comparing FRAX and NEON haplotypes, but these patterns were less clearly defined when APP was compared with the other two groups (Tables 3 and 4). Grey wolf mtDNA was common in 

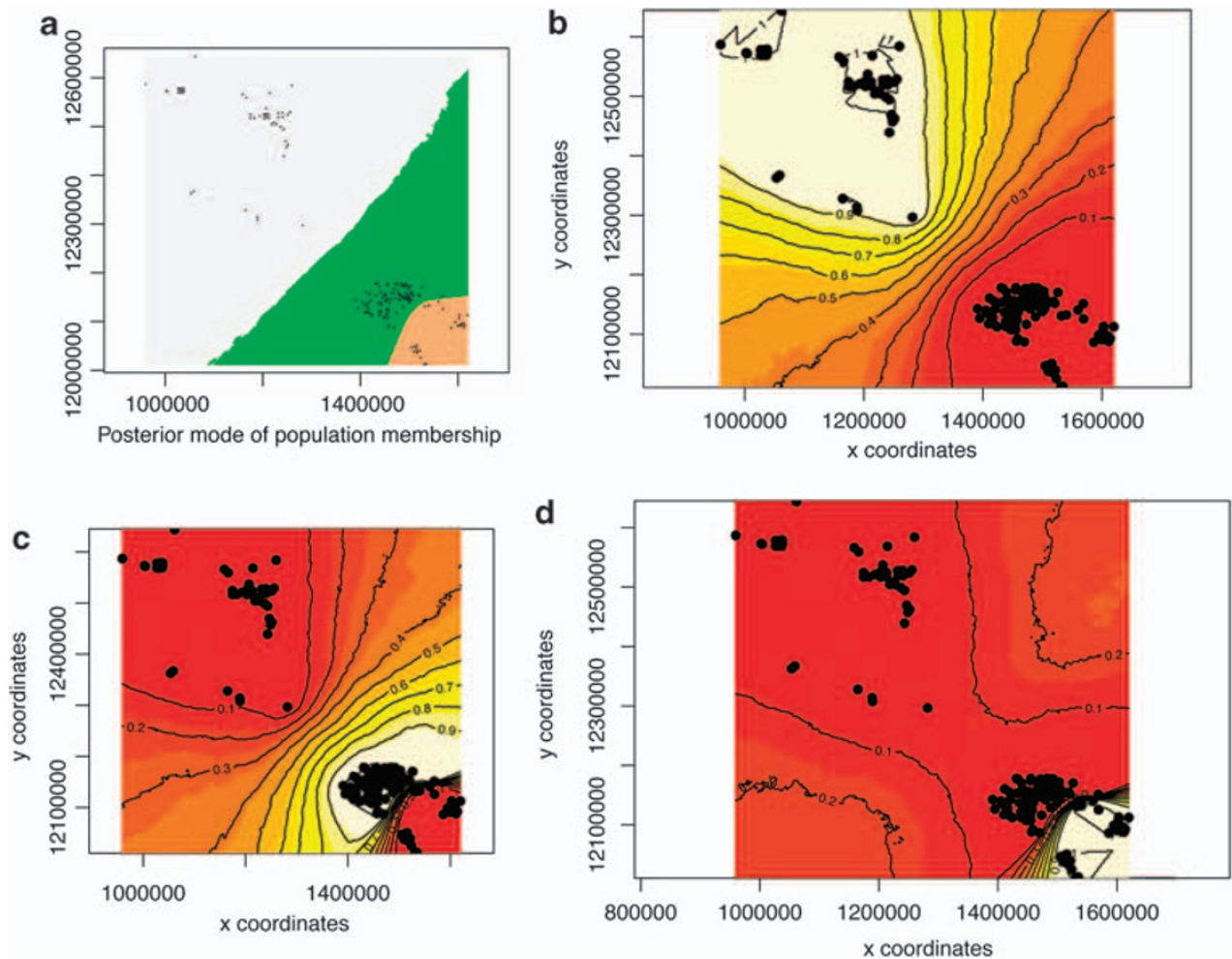

Figure 4 Spatial Bayesian clustering in the program Geneland. Black dots represent individual Canis samples. (a) Spatial clustering suggests three distinct clusters across geographic regions; (b) map of posterior probability of belonging to the northeastern Ontario (NEON) cluster; (c) map of the posterior probability of belonging to the Algonquin Provincial Park (APP) cluster; (d) map of the posterior probability of belonging to the southern Frontenac Axis (FRAX) cluster.

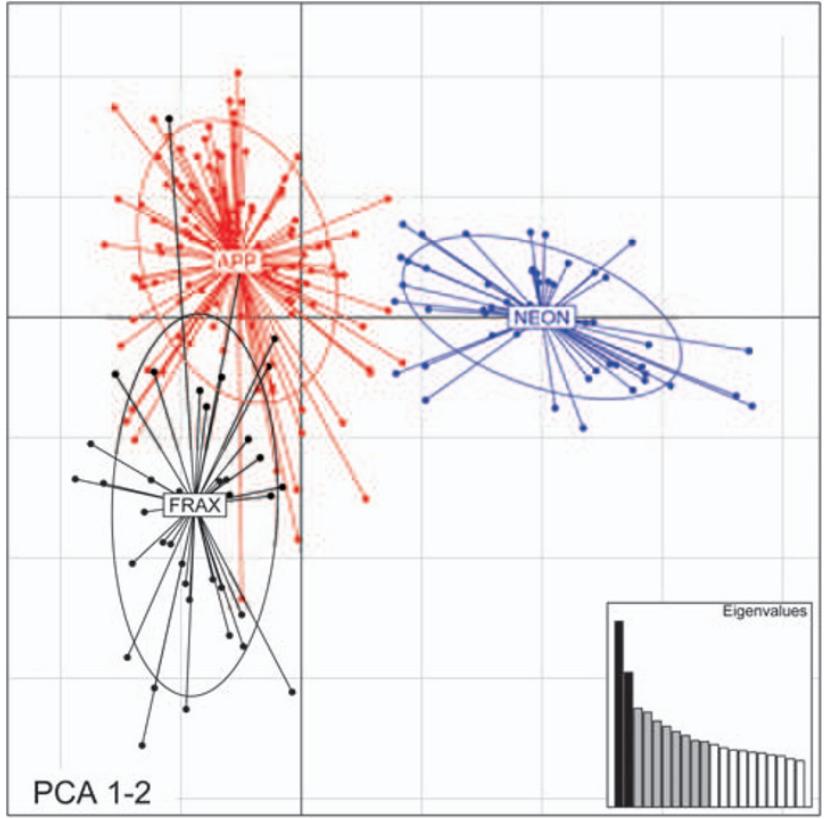

Figure 5 First and second components of a principal components analysis (PCA) of 12-locus microsatellite genotypes from 217 Canis samples from Ontario, Canada. APP, Algonquin Provincial Park; NEON, northeastern Ontario; FRAX, Frontenac Axis in southern Ontario. Ovals are 95\% inertia ellipses.

NEON with some evidence in APP but was absent from FRAX (Table 3). There were no coyote-specific $Y$ introns found in any of the regions, although APP and FRAX

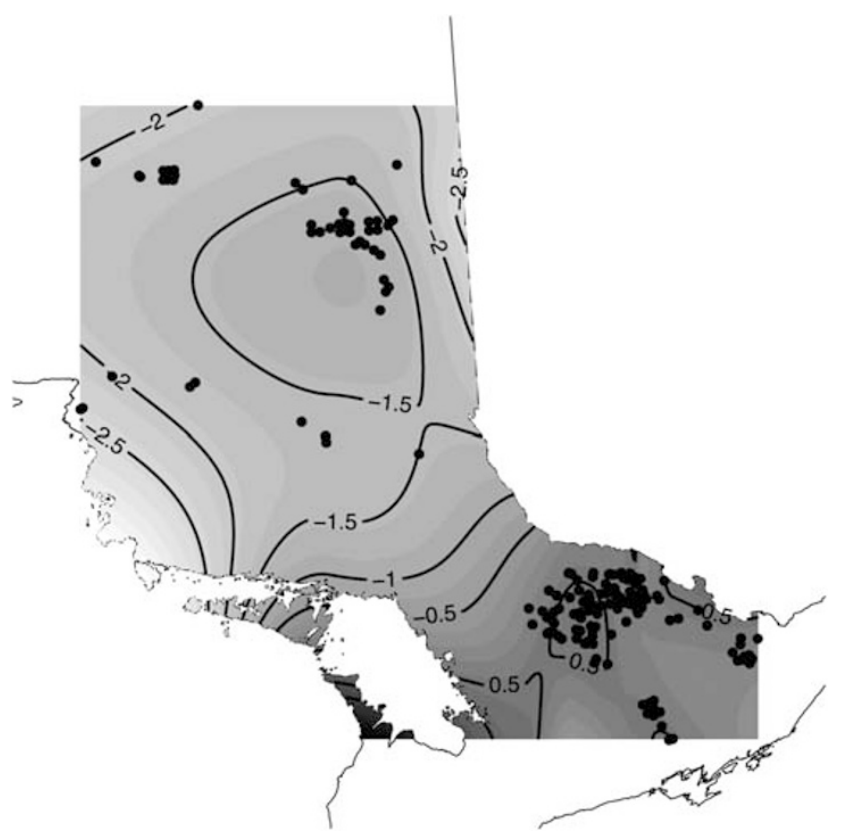

Figure 6 Component 1 from a spatial principal components analysis (sPCA) of 12-locus microsatellite genotypes from 217 Canis samples from Ontario, Canada, plotted on a map of Ontario. Dots are sample locations and contours are component scores that represent similarity across the landscape.

had Y introns and Y microsatellite haplotypes identified as ancestral haplotypes that evolved in North America (Shami, 2002; Wilson et al., in review; Table 4). This 
ancestral Y chromosome haplotype was absent from NEON. There was evidence of eastern wolf-specific mtDNA and $Y$ chromosome DNA in all three groups, although only one eastern wolf $Y$ chromosome haplotype was found in NEON (Table 4).

MtDNA haplotypes, Y chromosome haplotypes and assignment scores of all breeders identified in APP are shown in Table 5. Breeding wolves in APP tended to have high assignment to the Algonquin cluster and paired breeders were generally conspecific based on nuclear markers (Table 5). Of the 19 female breeders, 11 (57.9\%) had coyoto mtDNA haplotypes (C14, C19), 2 $(10.5 \%)$ had grey wolf mtDNA (C22) and $6(31.6 \%)$ had eastern wolf haplotypes (C9, C17) (Table 5). Twenty-nine of the 37 breeders $(78.4 \%)$ and 11 of the 15 breeding pairs $(73.3 \%)$ had high assignment scores $(Q \geqslant 0.8)$ to the APP cluster, whereas the remaining individuals or breeding pairs had varying levels of admixture between two or among all three clusters (Table 5). Of the 18 breeding males, $16(88.9 \%)$ had an eastern wolf $\mathrm{Y}$ chromosome haplotype (4AA, 4BB) with the other two having a grey wolf haplotype (2EF, 2CS); no male breeders had an ancestral or coyote $\mathrm{Y}$ chromosome haplotype (Table 5). Of all the male breeders, only those two with a grey wolf $\mathrm{Y}$ chromosome haplotype were identified as admixed individuals. The proportion of eastern wolf $\mathrm{Y}$ chromo-

Table 3 Mitochondrial DNA control region haplotypes in the three Canis clusters

\begin{tabular}{llcrrl}
\hline Haplotype & $\begin{array}{l}\text { GenBank } \\
\text { accession no. }\end{array}$ & $\begin{array}{c}\text { FRAX } \\
(\mathrm{n})\end{array}$ & $\begin{array}{c}\text { APP } \\
(\mathrm{n})\end{array}$ & $\begin{array}{c}\text { NEON } \\
(\mathrm{n})\end{array}$ & Origin \\
\hline C14 & AY267731 & 6 & 65 & 17 & Coyote \\
C19 & AY267736 & 6 & 33 & 0 & Coyote \\
C20 & AY267737 & 3 & 0 & 0 & Coyote \\
C1 & AY267718 & 9 & 3 & 0 & Eastern \\
C3 & AY267720 & 0 & 1 & 1 & Eastern \\
C9 & AY267726 & 14 & 7 & 0 & Eastern \\
C13 & AY267730 & 0 & 1 & 6 & Eastern \\
C17 & AY267734 & 0 & 8 & 0 & Eastern \\
C22 & FJ687608 & 0 & 9 & 17 & Grey \\
C23 & FJ687609 & 0 & 0 & 9 & Grey \\
C95 & FJ687610 & 0 & 0 & 1 & Grey \\
Missing & & 0 & 1 & 0 & \\
\hline
\end{tabular}

some haplotypes in APP breeding males was significantly higher than that expected from random mating across the complete $\mathrm{Y}$ chromosome microsatellite data set $(P<0.01)$ and that within APP $(P<0.02$; Figure 7$)$.

\section{Discussion}

Our study results clearly show that the three Canis populations in Ontario are genetically distinct, despite evidence of some contemporary gene flow. Current Canis species in North America diverged relatively recently, all sharing a common ancestor approximately 1-2 million years ago (Wilson et al., 2000), which may facilitate their successful mating when secondary contact occurs. Accordingly, the intermediate-sized wolves in APP contain a patchwork of genetic material derived from eastern wolves (C. lycaon), western coyotes (C. latrans) and grey wolves (C. lupus), having acted as a bridge for genetic exchange between grey wolves and coyotes. Animals in APP have, however, emerged as a distinct cohesive genetic unit despite hybridization with the other species. Under the framework of the Cohesion Species Concept whereby 'A species is the most inclusive population of individuals having the potential for phenotypic cohesion through intrinsic cohesion mechanisms' (Templeton, 1989), eastern wolves in APP can be defined as a separate species. Given the assortative mating patterns identified here, the mechanism by which these animals remain distinct may involve a SpecificMate-Recognition System whereby animals are able to recognize conspecifics as mates on the basis of behavioural, chemical or visual signals (Paterson, 1985; Coyne and Orr, 2004). The mechanism by which this occurs in wolves is not clear, but could presumably involve any one or all of these cues.

Patterns of maternal (mtDNA) and paternal ( $Y$ chromosome) inheritance indicate that introgression was, in general, sex biased with maternal DNA from the smaller coyote and paternal DNA from the larger grey wolf flowing across the landscape through eastern wolves. The presence of grey wolf mtDNA in APP and eastern wolf mtDNA in FRAX can be explained by introgression through hybrid backcrossing. Prevalence of eastern wolf mtDNA across the eastern United States

Table 4 Y chromosome haplotypes in the three Canis clusters

\begin{tabular}{|c|c|c|c|c|c|c|c|c|c|}
\hline Hap & Intron & MS34a & $M S 34 b$ & MS41a & $M S 41 b$ & $F R A X(\mathrm{n})$ & $A P P(\mathrm{n})$ & $N E O N(\mathrm{n})$ & Origin \\
\hline CD & 1 & 172 & 178 & 214 & 210 & 4 & 2 & 0 & A \\
\hline CR & 1 & 172 & 178 & 212 & 216 & 0 & 1 & 0 & A \\
\hline CI & 1 & 172 & 178 & 214 & 214 & 1 & 0 & 0 & A \\
\hline GP & 1 & 176 & 180 & 212 & 222 & 1 & 1 & 0 & A \\
\hline AA & 4 & 172 & 180 & 212 & 212 & 9 & 26 & 0 & EW \\
\hline BB & 4 & 170 & 182 & 212 & 226 & 0 & 14 & 1 & EW \\
\hline EF & 2 & 176 & 178 & 208 & 222 & 0 & 3 & 0 & GW \\
\hline $\mathrm{AF}$ & 2 & 172 & 180 & 208 & 222 & 0 & 0 & 4 & GW \\
\hline FL & 2 & 174 & 178 & 208 & 218 & 1 & 0 & 0 & GW \\
\hline HS & 2 & 174 & 176 & 208 & 226 & 1 & 0 & 0 & GW \\
\hline HT & 2 & 174 & 176 & 208 & 220 & 1 & 0 & 0 & GW \\
\hline CS & 2 & 172 & 178 & 208 & 226 & 0 & 3 & 0 & GW \\
\hline CE & 2 & 172 & 178 & 208 & 216 & 1 & 2 & 8 & GW \\
\hline CF & 2 & 172 & 178 & 208 & 222 & 0 & 0 & 5 & GW \\
\hline CT & 2 & 172 & 178 & 208 & 220 & 0 & 0 & 8 & GW \\
\hline CG & 2 & 172 & 178 & 208 & 224 & 0 & 1 & 0 & GW \\
\hline
\end{tabular}

Abbreviations: A, ancestral; EW, eastern wolf; GW, grey wolf; Hap, haplotype. 
Table 5 Assignment scores $(Q)$ of known breeders in APP wolf packs

\begin{tabular}{|c|c|c|c|c|c|c|}
\hline Individual ID & Gender & $\mathrm{Q}_{A P P}$ & $\mathrm{Q}_{F R A X}$ & $\mathrm{Q}_{N E O N}$ & $\begin{array}{l}\text { mtDNA } \\
\text { haplotype }\end{array}$ & $\begin{array}{l}\text { Y chromosome } \\
\text { haplotype }\end{array}$ \\
\hline \multicolumn{7}{|l|}{ Achray } \\
\hline W89/C4337 & $\mathrm{M}$ & 0.9621 & 0.0206 & 0.017 & $\mathrm{C} 14$ & $4 \mathrm{AA}$ \\
\hline W14/C4262 & $\mathrm{F}$ & 0.9567 & 0.0221 & 0.021 & C17 & NA \\
\hline W131/C4379 & M & 0.9687 & 0.021 & 0.01 & C14 & $4 \mathrm{AA}$ \\
\hline W44/C4292 & $\mathrm{M}$ & 0.975 & 0.009 & 0.0168 & $\mathrm{C} 14$ & $4 \mathrm{AA}$ \\
\hline \multicolumn{7}{|l|}{ Beechnut } \\
\hline W119/C4367 & $\mathrm{M}$ & 0.1866 & 0.2981 & 0.5153 & C14 & $2 \mathrm{EF}$ \\
\hline W130/C4378 & $\mathrm{F}$ & 0.843 & 0.0275 & 0.1295 & $\mathrm{C} 14$ & NA \\
\hline \multicolumn{7}{|l|}{ Bena } \\
\hline W21/C4269 & $\mathrm{M}$ & 0.8612 & 0.074 & 0.0648 & $\mathrm{C} 14$ & $4 \mathrm{AA}$ \\
\hline W42/C4290 & $\mathrm{F}$ & 0.8517 & 0.1383 & 0.01 & C19 & NA \\
\hline \multicolumn{7}{|l|}{ Big crow } \\
\hline W207/C4455 & $\mathrm{M}$ & 0.9514 & 0.0232 & 0.025 & C14 & $4 \mathrm{BB}$ \\
\hline W76/C4324 & $\mathrm{F}$ & 0.968 & 0.0211 & 0.011 & C14 & NA \\
\hline \multicolumn{7}{|l|}{ Cauliflower } \\
\hline W49/C4297 & $\mathrm{F}$ & 0.8054 & 0.1846 & 0.01 & C19 & NA \\
\hline W122/C4370 & $\mathrm{F}$ & 0.5678 & 0.3543 & 0.0778 & C19 & NA \\
\hline W16/C4264 & $\mathrm{F}$ & 0.9557 & 0.0221 & 0.022 & C19 & NA \\
\hline \multicolumn{7}{|l|}{ Flat iron } \\
\hline W58/C4306 & $\mathrm{F}$ & 0.948 & 0.0139 & 0.0383 & C17 & NA \\
\hline \multicolumn{7}{|l|}{ Jocko } \\
\hline W46/C4294 & $\mathrm{M}$ & 0.966 & 0.0236 & 0.0101 & $\mathrm{C} 14$ & $4 \mathrm{AA}$ \\
\hline W2/C4250 & $\mathrm{M}$ & 0.948 & 0.0311 & 0.0203 & C14 & $4 \mathrm{AA}$ \\
\hline W200/C4448 & $\mathrm{F}$ & 0.976 & 0.011 & 0.013 & $\mathrm{C} 22$ & NA \\
\hline \multicolumn{7}{|l|}{ LaFleur } \\
\hline W1/C4249 & $\mathrm{F}$ & 0.6474 & 0.1614 & 0.1911 & C9 & NA \\
\hline W4/C4252 & $\mathrm{F}$ & 0.2125 & 0.7398 & 0.0478 & C9 & NA \\
\hline \multicolumn{7}{|l|}{ Leaf } \\
\hline W13/C4261 & $\mathrm{F}$ & 0.7466 & 0.0659 & 0.1875 & C19 & NA \\
\hline W37/C4285 & $\mathrm{F}$ & 0.2878 & 0.2875 & 0.4248 & C19 & NA \\
\hline W68/C4316 & M & 0.9778 & 0.0163 & 0.006 & C19 & $4 \mathrm{AA}$ \\
\hline \multicolumn{7}{|l|}{ Louisa } \\
\hline W7/C4255 & $\mathrm{M}$ & 0.9387 & 0.0531 & 0.008 & C19 & $4 \mathrm{AA}$ \\
\hline W12/C4260 & $\mathrm{F}$ & 0.6081 & 0.369 & 0.023 & C19 & NA \\
\hline \multicolumn{7}{|l|}{ McKaskill } \\
\hline W50/C4298 & $\mathrm{M}$ & 0.7677 & 0.0954 & 0.137 & C14 & $2 \mathrm{CS}$ \\
\hline \multicolumn{7}{|l|}{ Pine } \\
\hline W91/C4339 & $\mathrm{M}$ & 0.973 & 0.015 & 0.013 & $\mathrm{C} 17$ & $4 \mathrm{AA}$ \\
\hline W45/C4293 & $\mathrm{F}$ & 0.9401 & 0.0475 & 0.012 & $\mathrm{C} 14$ & NA \\
\hline \multicolumn{7}{|l|}{ Potter } \\
\hline W90/C4338 & $\mathrm{M}$ & 0.9666 & 0.013 & 0.02 & C14 & $4 \mathrm{BB}$ \\
\hline W190/C4438 & $\mathrm{M}$ & 0.9527 & 0.0279 & 0.0197 & C14 & $4 \mathrm{BB}$ \\
\hline \multicolumn{7}{|l|}{ Pretty } \\
\hline W65/C4313 & M & 0.983 & 0.01 & 0.006 & $\mathrm{C} 17$ & $4 \mathrm{AA}$ \\
\hline W66/C4314 & $\mathrm{F}$ & 0.978 & 0.012 & 0.01 & $\mathrm{C} 22$ & NA \\
\hline \multicolumn{7}{|l|}{ Radiant } \\
\hline W84/C4332 & $\mathrm{M}$ & 0.980 & 0.009 & 0.011 & C14 & $4 \mathrm{AA}$ \\
\hline W62/C4310 & $\mathrm{F}$ & 0.9102 & 0.0267 & 0.0632 & C14 & NA \\
\hline \multicolumn{7}{|l|}{ Spoor } \\
\hline W125/C4373 & M & 0.9606 & 0.01 & 0.0294 & $\mathrm{C} 22$ & $4 \mathrm{AA}$ \\
\hline W124/C4372 & $\mathrm{F}$ & 0.8813 & 0.0259 & 0.0928 & C19 & NA \\
\hline \multicolumn{7}{|l|}{ Sunday } \\
\hline W180/C4428 & $\mathrm{M}$ & 0.9209 & 0.026 & 0.053 & C19 & $4 \mathrm{BB}$ \\
\hline W25/C4273 & $\mathrm{F}$ & 0.9455 & 0.0441 & 0.01 & C14 & NA \\
\hline
\end{tabular}

Abbreviations: F, female; M, male; NA, not applicable.

Pack names are given at the centre top of each group. Bold IDs show breeding pairs that produced offspring. Assignment scores are the probability values based on output from the program Structure and those in bold highlight either high assignment to APP $(Q \geqslant 0.8)$ or various levels of admixture. Species designations of mtDNA and Y chromosome hapltoypes are indicated in Tables 3 and 4, respectively. 


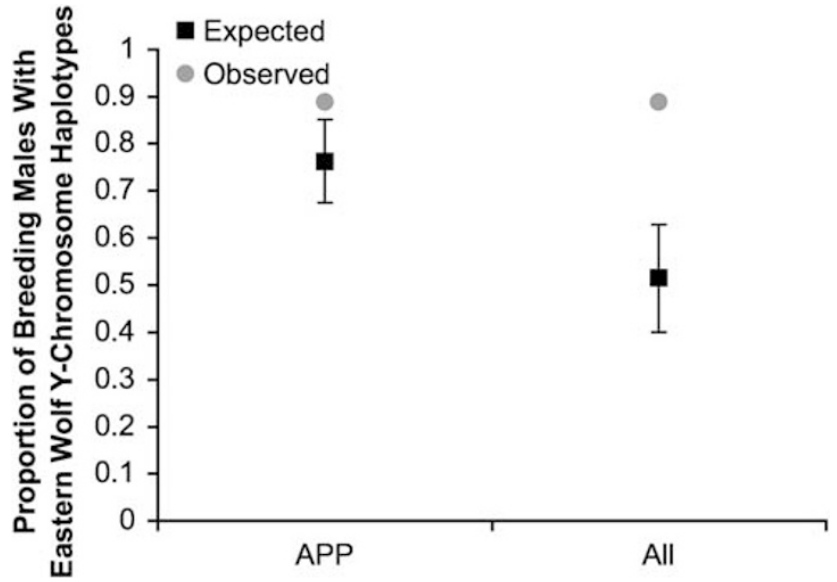

Figure 7 Observed proportion of eastern wolf $\mathrm{Y}$ chromosome haplotypes in Algonquin Provincial Park (APP) compared with that expected if males were breeding randomly. Randomization tests were conducted by randomly selecting $18 \mathrm{Y}$ chromosome haplotypes from all possible $\mathrm{Y}$ chromosome haplotypes within APP $(P<0.02)$ and across all populations $(P<0.01)$. Expected values are based on 100 permutations. Error bars are the standard deviation.

(Kays et al., 2010; Way et al., 2010) suggests that the size hypothesis may be less applicable in the case of eastern wolf-coyote hybridization, but does not preclude the general trend observed in our data set where coyote mtDNA was present in NEON grey wolves but coyote and ancestral $\mathrm{Y}$ chromosome DNA was absent, and grey wolf mtDNA was present in FRAX coyotes but grey wolf $Y$ chromosome DNA was absent.

The Bayesian and multivariate analyses used in this study revealed a complex history of repeated hybridization events in Ontario Canis populations. Our data support previous findings that show three genetic clusters in Ontario segregating as the near north Ontario grey wolf (also known as the 'boreal-type wolf', 'Ontario-type wolf' (Kolenosky and Standfield, 1975), or 'Great Lakes wolf' (Leonard and Wayne, 2008)), the APP eastern wolf and the eastern coyote (also referred to as the 'Tweed-type wolf' (Kolensoky and Standfield, 1975)) with some evidence of admixture, migration and a genetic cline across a latitudinal gradient; genetic material from C. lycaon is persistent across study regions. Overall, however, ongoing introgression is limited, possibly because of reproductive barriers in Algonquin animals that limit genetic exchange with neighbouring populations. Concentric sampling in areas outside the park, including Quebec, will be required to identify the full extent of the population of Algonquin-like canids.

Our interpretation is different from previous suggestions that Algonquin animals represent the southern edge of a larger metapopulation (Grewal et al., 2004; Wilson et al., 2009), but is consistent with morphological and ecological data that support the Algonquin animals as distinct from surrounding populations (Kolenosky and Standfield, 1975; Theberge and Theberge, 2004; Holloway, 2010). Although results from both the current and previous studies suggest gene flow across a cline, homogeneous neighbouring populations are not evident; the three Canis groups remain quite distinct. This apparent contradiction is illusory, however, as genetic exchange does not preclude differentiation, and evidence of gene flow at neutral markers is not necessarily indicative of sharing of coding regions responsible for phenotypic traits that are selected for in 'ecologically specialized populations' (Via, 2009). Future work that focuses on quantitative trait loci for morphological and behavioural features in Canis species, in conjunction with specific measurements of ecological variables, could be helpful in further understanding the role that divergent selection is having on Canis speciation. Differentiation in wolves is most likely linked to prey specialization (Carmichael et al., 2001; Muñoz-Fuentes et al., 2009). Therefore, if moose persists in APP, selection may favour larger eastern wolves either through natural selection on current morphological variation or through increased hybridization with larger grey wolves north of the park. Alternatively, transmission of learned behaviour through generations may be sufficient to allow wolves in Algonquin to exploit this large-bodied prey despite their relatively small stature. Regardless of the mechanism, protecting connected habitats will be important for gene flow into the park to maximize standing genetic variation on which selection can act.

We have documented a tendency for conspecific mating within the Algonquin wolf population. Assortative mating has a particularly important role in speciation because it is one of the main factors affecting ecological speciation events (Coyne and Orr, 2004; Schluter, 2009). Initially, divergent selection can influence reproductive fitness if hybrids are less fit than parental types (Schluter, 2001). Conspecific mate choice may provide a mechanism by which Algonquin animals are able to exclude hybrid species in neighbouring regions. Identifying the specific sensory cues involved in mate choice would help clarify how wolves identify conspecifics and what role that may have in ecological speciation.

In broad evolutionary terms, these results provide important insight into how mating patterns influence differentiation after hybridization. More specifically, however, the results of our study have important conservation implications for wild Canis species in eastern North America. The primary goal of conservation science is to conserve the genetic building blocks within species so that the evolutionary processes that contribute to ecological viability are minimally constrained. Eastern wolves are currently identified as a species of 'Special Concern' under the Committee on the Status of Endangered Wildlife in Canada and the Committee on the Status of Species at Risk in Ontario, but hybridization has complicated efforts to identify distinctive populations. The data presented here suggest that wolves in APP are morphologically and genetically distinct from Canis hybrids in other regions of Ontario, and contain a substantial proportion of the historic eastern wolf genome. Although range delineation of the APP population may be complicated by ongoing gene flow, this population constitutes a substantive, rare and likely ecologically diverged entity, and as such should be treated as a distinct conservation unit.

\section{Conflict of interest}

The authors declare no conflict of interest. 


\section{Acknowledgements}

Thank you to Tyler Wheeldon for providing the NEON genetic data and to Tim Frasier for analytical help. We acknowledge provision of samples and/or weight measurements by Ken Mills and Josh Holloway. We thank Brad White, Chris Wilson and Paul Wilson for their comments on various versions of this paper. Thanks to the field crew, others who provided samples, and to lab technicians Smolly Coulson and Jen Dart at the Natural Resources DNA Profiling and Forensic Centre. This research was funded by the Ontario Ministry of Natural Resources and a Natural Sciences Engineering and Research Council of Canada post-graduate doctoral scholarship awarded to Linda Rutledge.

\section{References}

Aasen E, Medrano J (1990). Amplification of the ZFY and ZFX genes for sex identification in humans, cattle, sheep and goats. Nat Biotechnol 8: 1279-1281.

Allendorf F, Leary R, Spruell P, Wenburg J (2001). The problems with hybrids: setting conservation guidelines. Trends Ecol Evol 16: 613-622.

Arnold M (2006). The role of species concepts. In: Arnold M (ed). Evolution Through Genetic Exchange. Oxford University Press: Oxford. pp 23-33.

Berger K, Gese E (2007). Does interference competition with wolves limit the distribution and abundance of coyotes? J Anim Ecol 76: 1075-1085.

Carmichael L, Nagy J, Larter N, Strobeck C (2001). Prey specialization may influence patterns of gene flow in wolves of the Canadian Northwest. Mol Ecol 10: 2787-2798.

Coulon A, Guillot G, Cosson J-F, Angibault J, Aulangnier S, Cargnelutti B et al. (2006). Genetic structure is influenced by landscape features: empirical evidence from a roe deer population. Mol Ecol 15: 1669-1679.

Coyne J, Orr H (2004). Speciation. Sinauer Associates Inc.: Sunderland, MA.

Crawford N (2009). SMOGD: software for the measurement of genetic diversity. Mol Ecol Notes (doi:10.111/j.1755-0998. 2009.02801.x).

Dobzhansky T (1937). Genetics and the Origin of Species. Columbia University Press: New York.

Dray S, Dufour A (2007). The ade4 package: implementing the duality diagram for ecologists. J Stat Softw 22: 1-20.

Evanno G, Regnaut S, Goudet J (2005). Detecting the number of clusters of individuals using the software STRUCTURE: a simulation study. Mol Ecol 14: 2611-2620.

Fain S, LeMay J (1995). Gender identification of humans and mammalian wildlife species from PCR amplified sex linked genes. Proc Am Acad Forensic Sci 1: 34.

Falush D, Stephens M, Pritchard J (2003). Inference of population structure using multilocus genotype data: linked loci and correlated allele frequencies. Genetics 164: 1567-1587.

Forbes G, Theberge J (1996). Response to prey variation by wolves in north-central Ontario. Can J Zool 74: 1511-1520.

Frantz A, Cellina S, Krier A, Schley L, Burke T (2009). Using spatial Bayesian methods to determine the genetic structure of a continuously distributed population: clusters or isolation by distance? J Appl Ecol 46: 493-505.

Futuyma D (2005). Evolution. Sinauer Associates Inc.: Sunderland, MA.

Grewal S, Wilson P, Kung T, Shami K, Theberge M, Theberge J et al. (2004). A genetic assessment of the eastern wolf (Canis lycaon) in Algonquin Provincial Park. J Mammal 85: 625-632.

Guillot G, Estoup A, Mortier F, Cosson J (2005). A spatial statistical model for landscape genetics. Genetics 170: $1261-1280$.
Guillot G, Santos F, Estoup A (2008). Analysing georeferenced population data with Geneland: a new algorithm to deal with null alleles and a friendly graphical user interface. Bioinformatics 24: 1406-1407.

Hailer F, Leonard JA (2008). Hybridization among three native North American Canis species in a region of natural sympatry. PLoS One 3: e3333.

Hall T (2007). BioEdit v7 http:/ / www.mbio.ncsu.edu/BioEdit/ BioEdit.html.

Hedrick P (2005). A standardized genetic differentiation measure. Evolution 59: 1633-1638.

Holloway J (2010). Size dependent resource use of a hybrid wolf (Canis lycaon $x$ C. lupus) population in northeast Ontario. Masters thesis, Trent University, Peterborough: Ontario, Canada.

Jombart T (2008). adegenet: a $\mathrm{R}$ package for the multivariate analysis of genetic markers. Bioinformatics 24: 1403-1405.

Jombart T, Devillard S, Dufour A-B, Pontier D (2008). Revealing cryptic spatial patterns in genetic variability by a new multivariate method. Heredity 101: 92-103.

Jost L (2008). G ST $_{\text {T }}$ and its relatives do not measure differentiation. Mol Ecol 17: 4015-4026.

Jost L (2009). D vs. $G_{\mathrm{ST}}$ : response to Heller and Siegismund (2009) and Ryman and Leimar (2009). Mol Ecol 18: 2088-2091.

Kays R, Curtis A, Kirchman JJ (2010). Rapid adaptive evolution of northeastern coyotes via hybridization with wolves. Biol Lett 6: 89-93 (doi:10.1098/rsbl.2009.0575).

Kolenosky G, Standfield O (1975). Morphological and ecological variation among grey wolves (Canis lupus) of Ontario, Canada. In: Fox M (ed.). The Wild Canids. Van Nostrand Reinhold: New York, pp 62-72.

Legendre P, Legendre L (1998). Numerical Ecology. Elsevier Science: Amsterdam.

Leonard JA, Wayne RK (2008). Native Great Lakes wolves were not restored. Biol Lett 4: 95-98.

Li Y-C, Korol A, Fahima T, Beiles A, Nevo E (2002). Microsatellites: genomic distribution, putative functions and mutational mechanisms: a review. Mol Ecol 11: 2453-2465.

Loveless K (2010). Foraging strategies of eastern wolves in relation to migratory prey and hybridization. Masters thesis, Trent University, Peterborough: Ontario, Canada.

Mallet J (2005). Hybridization as an invasion of the genome. Trends Ecol Evol 20: 229-237.

Mayr E (1942). Systematics and the Origin of Species. Columbia University Press: New York.

Merkle J, Stahler D, Smith D (2009). Interference competition between grey wolves and coyotes in Yellowstone National Park. Can J Zool 87: 52-63.

Moran P (1948). The interpretation of statistica maps. J R Stat Soc Ser B 10: 243-251.

Moran P (1950). A test for the serial independence of residuals. Biometrika 37: 178-181.

Mu V, Darimont C, Wayne R, Paquet P, Leonard J (2009). Ecological factors drive differentiation in wolves from British Columbia. J Biogeogr 36: 1516-1531.

Ostrander E, Mapa F, Yee M, Rine J (1995). One hundred and one new simple sequence repeat-based markers for the canine genome. Mamm Genome 6: 192-195.

Ostrander E, Sprague G, Rine J (1993). Identification and characterization of dinucleotide repeat (CA)n markers for genetic mapping in dog. Genomics 16: 207-213.

Paterson HEH (1985). The recognition concept of species. In: Vrba ES (ed). Species and Speciation. Transvall Museum Monograph No. 4: Pretoria, pp 21-29.

Peakall R, Smouse P (2006). GENALEX 6: genetic analysis in Excel. Population genetic software for teaching and research. Mol Ecol Notes 6: 288-295.

Pilgrim K, Boyd D, Forbes S (1998). Testing for wolf-coyote hybridization in the Rocky Mountains using mitochondrial DNA. J Wildl Manage 62: 683-689. 
Pimlott DH, Shanon JA, Kolenosky GB (1969). The ecology of the timber wolf in Algonquin Provincial Park. Ontario Ministry of Natural Resources: Toronto, Ontario. Report no. 87.

Pritchard J, Stephens M, Donnelly P (2000). Inference of population structure using multilocus genotype data. Genetics 155: 945-959.

Quinn N (2005). Reconstructing changes in abundance of white-tailed deer, Odocoilus virginianus, moose, Alces alces, and beavers, Castor canadensis, in Algonquin Park, Ontario, 1860-2004. Can Field Nat 119: 330-342.

R Development Core Team (2008). R: A Language and Environment for Statistical Computing. Vienna: Austria. ISBN 3-900051-07-0, URL http://www.R-project.org.

Rhymer J, Simberloff D (1996). Extinction by hybridization and introgression. Annu Rev Ecol Syst 27: 83-189.

Rutledge L, Bos K, Pearce R, White B (2009). Genetic and morphometric analysis of sixteenth century Canis skull fragments: implications for historic eastern and grey wolf distribution in North America. Conserv Genet (doi:10.1007/ 210592-1009-9957-2)

Rutledge L, Patterson B, Mills K, Loveless K, Murray D, White B (2010). Protection from harvesting restores the natural social structure of eastern wolf packs. Biol Conserv 143: 332-339 (doi: 10.1016/j.biocon.2009.10.017).

Schluter D (2001). Ecology and the origin of species. Trends Ecol Evol 16: 373-380.

Schluter D (2009). Evidence for ecological speciation and its alternative. Science 323: 737-741.

Schwartz M, McKelvey K (2009). Why sampling scheme matters: the effect of sampling scheme on landscape genetic results. Conserv Genet 10: 441-452.

Sears H (1999). A landscape based assessment of Canis morphology, ecology and conservation in southeastern Ontario. Masters thesis, University of Waterloo, Waterloo: Ontario, Canada.

Sears H, Theberge J, Theberge M, Thornton I, Campbell D (2003). Landscape influence on Canis morphological and ecological variation in a coyote-wolf $C$. lupus $x$ latrans hybrid zone, southeastern Ontario. Can Field Nat 117: 589-600.

Seehausen O (2004). Hybridization and adaptive radiation. Trends Ecol Evol 19: 198-207.

Shami K (2002). Evaluating the change in distribution of the eastern timber wolf (Canis lycaon) using the Y-chromosome.
Masters thesis, McMaster University, Hamilton: Ontario, Canada, 73 pp.

Shaw C, Wilson P, White B (2003). A reliable molecular method of gender determination for mammals. J Mammal 84: 123-128.

Slatkin M (1995). A measure of population subdivision based on microsatellite allele frequencies. Genetics 139: 457-462.

Sundqvist A, Ellegren H, Olivier M, Vilà C (2001). Y chromosome haplotyping in Scandinavian wolves (Canis lupus) based on microsatellite markers. Mol Ecol 10: 1959-1966.

Templeton AR (1989). The meaning of species and speciation: a genetic perspective. In: Otte D, Endler JA (eds). Speciation and its Consequences. Sinauer Associates: Sunderland, MA, pp 3-27.

Theberge J, Theberge M (2004). The Wolves of Algonquin Park: A 12 Year Ecological Study. Publication series number 56 Department of Geography, University of Waterloo, Waterloo: Canada.

Via S (2009). Natural selection in action during speciation. Proc Natl Acad Sci USA 106: 9939-9946.

Way J, Rutledge LY, Wheeldon T, White BN (2010). Genetic characterization of northeastern coyotes in eastern Massachusetts. Northeast Nat. (in press).

Weir B, Cockerham C (1984). Estimating F-statistics for the analysis of population structure. Evolution 38: 1358-1370.

Wheeldon T (2009). Genetic characterization of Canis populations in the Western Great Lakes Regions. Masters thesis, Trent University, Peterborough: Ontario, Canada, 120 pp.

Wheeldon T, White B (2009). Genetic analysis of historic western Great Lakes region wolf samples reveals early Canis lupus/lycaon hybridization. Biol Lett 5: 101-104.

Wilson P, Grewal P, McFadden T, Chambers R, White B (2003). Mitochondrial DNA extracted from eastern North American wolves killed in the 1800 s is not of grey wolf origin. Can J Zool 81: 936-940.

Wilson P, Grewal S, Lawford I, Heal J, Granacki A, Pennock D et al. (2000). DNA profiles of the eastern Canadian wolf and the red wolf provide evidence for a common evolutionary history independent of the grey wolf. Can J Zool 78: 2156-2166.

Wilson P, Grewal S, Mallory F, White B (2009). Genetic characterization of hybrid wolves across Ontario. J Hered 100(Suppl 1): S80-S89.

Wilson P, Shami K, Wheeldon T, Rutledge L, Patterson B, White B (in review). Widespread signatures of three-species Canis hybridization in eastern North America. Biol Lett. 